\title{
Postpartum Genital Melanoma - A Case Report
}

\section{Melanoma genital pós-parto - relato de caso}

\author{
Gisele Alborghetti Nai ${ }^{1}$ Andressa Bazan ${ }^{1}$ Caroline Andrade Rocha ${ }^{1} \quad$ Juliana Souza Nagy ${ }^{1}$ \\ Isadora Tanaka Campos ${ }^{1}$
}

${ }^{1}$ Faculdade de Medicina, Universidade do Oeste Paulista, Presidente Prudente, São Paulo, Brazil

Rev Bras Ginecol Obstet 2018;40:163-167.

\begin{abstract}
Address for correspondence Gisele Alborghetti Nai, MD, PHD, Laboratório de Anatomia Patológica e Citopatologia, Universidade do Oeste Paulista, Rua José Bongiovani, 700, Presidente Prudente, SP 19050-680, Brazil (e-mail: patologia@unoeste.br).
\end{abstract}

\author{
Abstract \\ Keywords \\ - melanoma \\ - vaginal neoplasms \\ - pregnancy \\ - estrogens \\ - prognosis
}

\section{Resumo}

Melanomas of the female genital tract may occur in the vulva, the vagina, the ovary or the cervix. Pregnancy has been considered an aggravating factor in the evolution and prognosis of melanoma. A 35-year-old female presented with vaginal bleeding 2 months after a term cesarean delivery. An endovaginal ultrasound revealed a lesion in the uterine cervix. The pathological report revealed a small round-cell neoplasm, and the immunohistochemistry confirmed the diagnosis of malignant melanoma. A positron emission tomography revealed an expansive hypermetabolic lesion centered on the cervix, and hypermetabolic lesions in the liver and right kidney. Non-surgical treatment was provided, with biochemotherapy followed by ipilimumab and nivolumab. The patient died one year later. Postpartum vaginal bleeding, even if late-onset, should be investigated, as it may be a pregnancy-associated malignant melanoma, which has a poor prognosis.

Melanomas do trato ginecológico podem ocorrer na vulva, vagina, ovário ou cérvix. A gravidez é considerada um fator agravante na evolução e prognóstico do melanoma. Uma mulher de 35 anos de idade apresentou sangramento vaginal 2 meses após o parto por cesariana a termo. Uma ultrassonografia endovaginal mostrou lesão no colo uterino. 0 exame anatomopatológico mostrou uma pequena neoplasia de células redondas, e a imuno-histoquímica confirmou o diagnóstico de melanoma maligno. A tomografia por emissão de pósitrons mostrou lesão hipermetabólica expansiva centrada no colo do útero, e lesões hipermetabólicas no fígado e no rim direito. O tratamento não cirúrgico foi feito com bioquimioterapia seguida de ipilimumab e nivolumab. A paciente morreu um ano depois. Sangramentos vaginais pós-parto, mesmo que tardios, devem ser investigados, pois podem ser um melanoma maligno associado à gravidez, o qual tem um mau prognóstico.

\section{Introduction}

Melanomas are malignant neoplasms originating from melanocytes. Although most of them originate in the skin, other sites of onset include the oral cavity, the esophagus, the anus, the conjunctiva or the female genital tract. The melanomas of the female genital tract are divided into vulvar, vaginal, ovarian or cervical. ${ }^{1}$

received

October 3, 2017

accepted

December 20, 2017

published online

February 23, 2018
Mucosal melanoma accounts for $\sim 5 \%$ of all melanomas. Melanomas of the female genital tract are rare, accounting for less than $10 \%$ of the melanomas diagnosed in women; however, they have a worse prognosis. There are fewer than 300 cases of genital melanomas reported worldwide. ${ }^{2}$

Compared with cutaneous melanoma, vaginal melanoma has a worse prognosis, with a 5 -year overall survival rate of $5 \%$ to $32.3 \%$. Melanoma is the most common malignant

Copyright $\odot 2018$ by Thieme Revinter Publicações Ltda, Rio de Janeiro, Brazil 


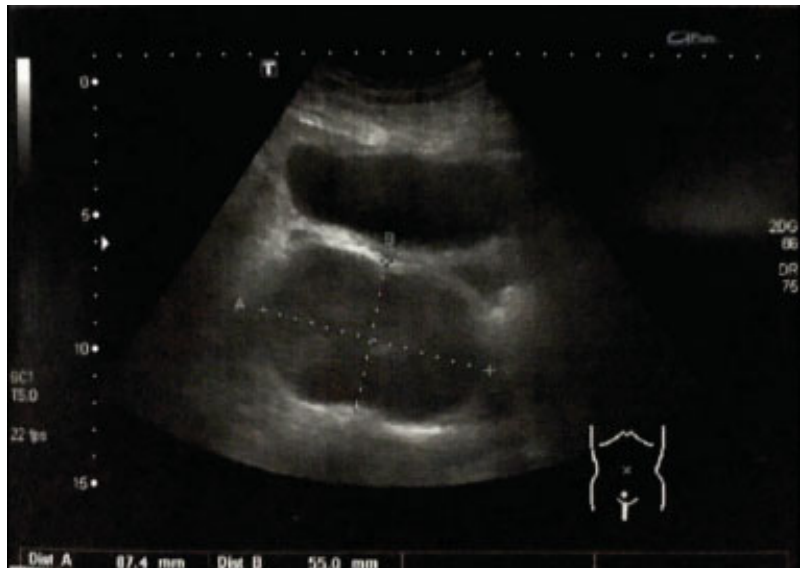

Fig. 1 Transvaginal ultrasound with a hypoechogenic image in the uterine cervix.

neoplasm reported during pregnancy, and the second most common in the postpartum period, second only to breast cancer. The incidence of melanoma in pregnancy varies from 2.8 to 5.0 per 100,000 pregnancies. Pregnancy has been considered an aggravating factor in the progression and prognosis of melanoma. ${ }^{1}$

The present paper aims to report a case of genital melanoma diagnosed in a puerperal woman, which demonstrates the evolution of the pathology and poor prognosis of melanoma during the course of pregnancy.

\section{Case Report}

A 35-year-old female Caucasian primigravid patient, who was otherwise healthy, without changes to the Pap test and to the genital examination during the prenatal care, presented two months after a full-term cesarean delivery with vaginal bleeding after resuming the use of progestogenbased contraceptives. The contraceptive was subsequently replaced with a combination agent of estrogen and progestin.

After three months, the patient presented again with a new episode of vaginal bleeding. A transvaginal ultrasound revealed a lesion in the projection of the uterine cervix, which increased significantly in volume, measuring $40 \mathrm{~mm}$ on a repeat transvaginal ultrasound performed 15 days later (- Fig. 1 ).

A needle biopsy guided by ultrasound was performed, with a histological pathology report of small round-cell malignancies (-Fig. 2A) and immunohistochemical studies that revealed positivity to $S 100$ protein and melanoma antigen recognized by T cells - Melan A (MART1) ( - Figs. 2B and 2C) and negativity to desmin (smooth muscle actin) and cytokeratins AE1/AE3, confirming the diagnosis of malignant melanoma. A search for estrogen and progesterone receptors and the mutation of the BRAF gene in the tumor yielded negative results.

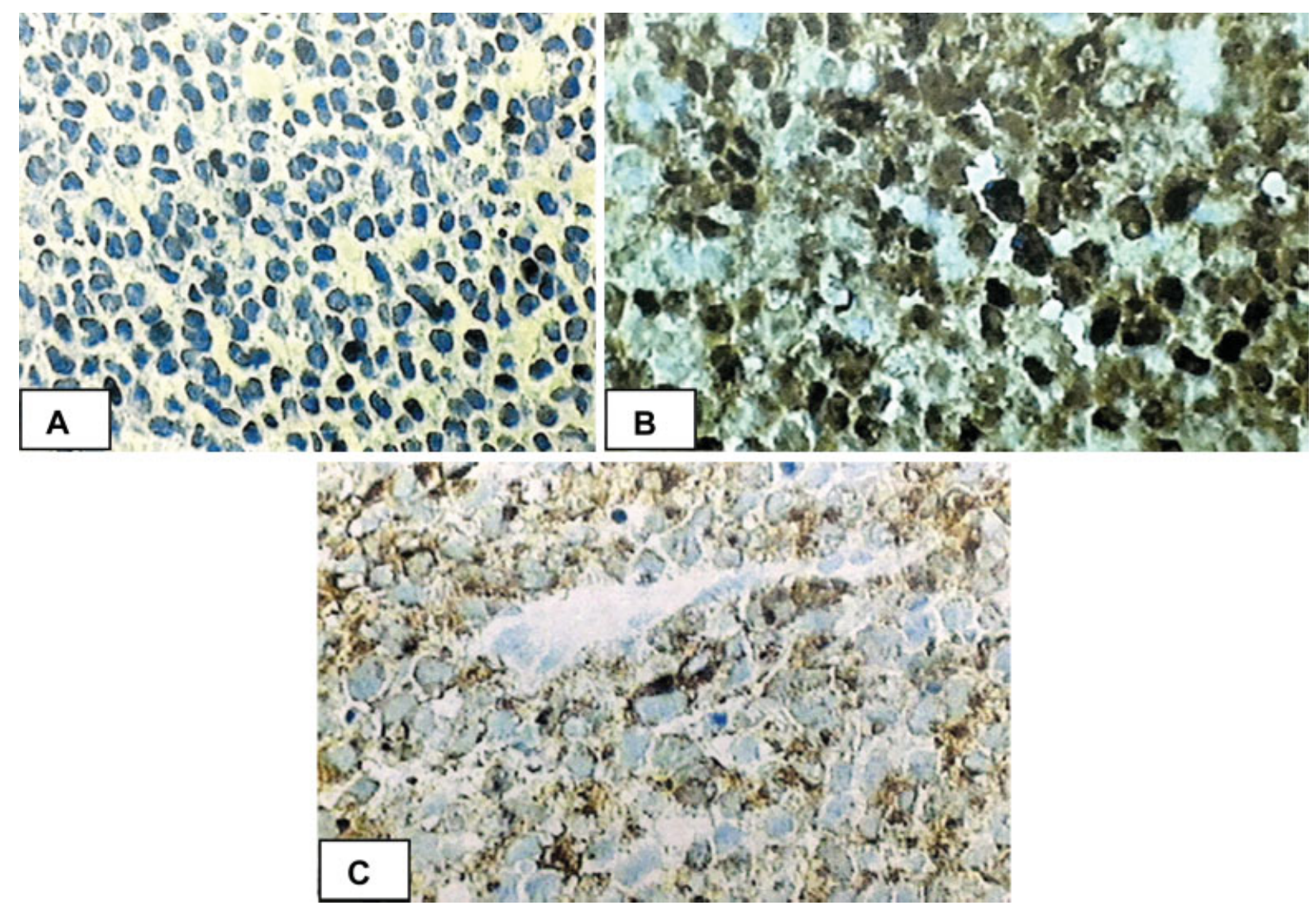

Fig. 2 Photomicroscopy of the genital mass. (A) Proliferation of small and round cells with nuclear hyperchromasia forming bed sheets (hematoxylin-eosin, 400x magnification). (B) Positive immunoblotting for S100 protein antibody (polyclonal clone, 400x magnification). (C) Positive immunoblotting for Melan A antibody (MART-1) (clone A103, 400x magnification). 

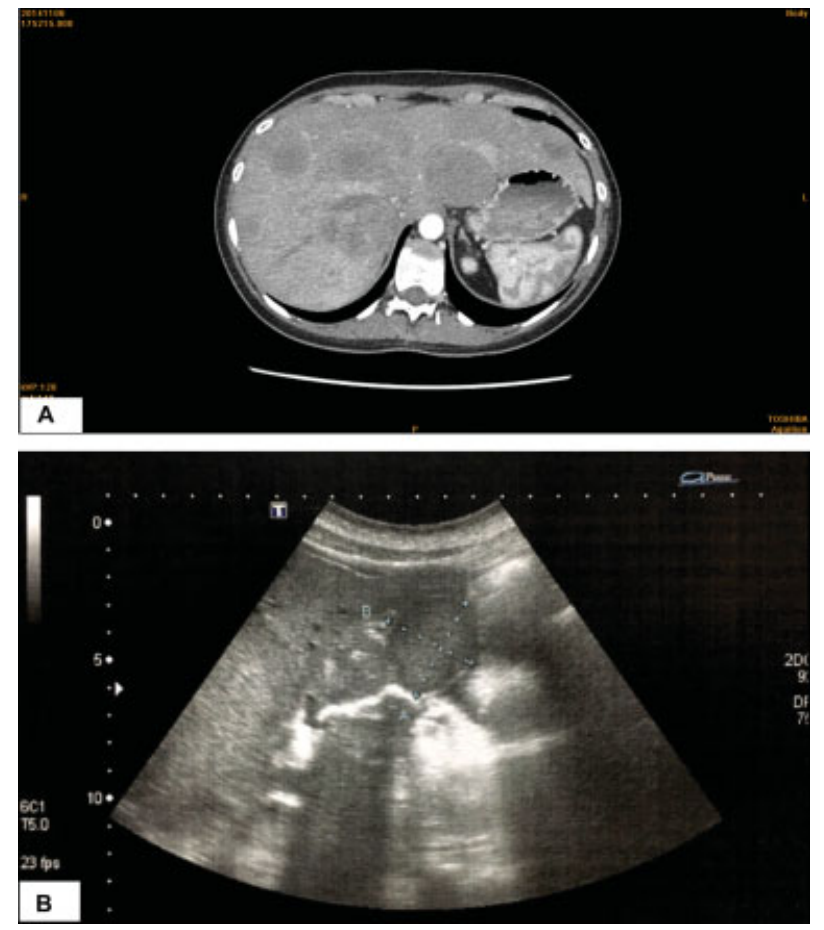

Fig. 3 (A) Computed tomography scan with hypoattenuating lesions in the hepatic parenchyma (arrows). (B) Abdominal ultrasound showing hypoechoic images in the liver

A computed tomography (CT) scan of the thorax revealed the absence of pulmonary or mediastinal lesions and the presence of hypoattenuating lesions in the hepatic parenchyma ( $\boldsymbol{- F i g . ~ 3 A ) , ~ w h i c h ~ w e r e ~ a l s o ~ o b s e r v e d ~ o n ~ a n ~ a b d o m i n a l ~}$ ultrasound ( - Fig. 3B). A positron emission tomography/computed tomography (PET/CT) scan with fluorine-18 fluorodeoxyglucose (F18-FDG) revealed a hypermetabolic expansive lesion in the uterine cervix and hypermetabolic lesions in the liver and right kidney (-Fig. 4). Thus, the non-surgical treatment was chosen.

The patient underwent two sessions of biochemotherapy three weeks apart. Post-treatment PET/CT with F18-FDG revealed no significant alterations in the expansive/infiltrative lesion and persistence of the hepatic lesions, several of which exhibited a slight increase in size compared with the previous study. The patient subsequently underwent a third biochemotherapy session. A repeat PET/CT with F18-FDG was performed, showing tumor progression, and this treatment was ended.

Ipilimumab (195 mg), an anti-cytotoxic T lymphocyte-associated antigen 4 (anti-CTLA-4) monoclonal antibody (IgG1k), was then administered. After three applications, the treatment was discontinued, as no improvement was observed. Subsequently, nivolumab, a humanized monoclonal antibody of immunoglobulin G4 against programmed cell death protein 1 (PD-1), was administered. After the fourth application, the patient presented with hepatic insufficiency, and the treatment was suspended. The patient subsequently underwent three mild radiotherapy sessions. One year after the diagnosis, the patient died.

The patient's husband signed the informed consent form, authorizing the publication of the case. This report was approved by the Research Ethics Committee of Universidade do Oeste Paulista (under CAAE no. 68672017.9.0000.5515).

\section{Discussion}

Vaginal melanoma is rare, being the second most frequent melanoma of the female genital tract (21\%) after vulvar melanoma (70\%). The etiology of genital melanoma is unknown. Risk factors, such as the human papilloma virus (HPV) subtype 16, radiotherapy or estrogen, have been proposed by Myriokefalitaki et al. ${ }^{3}$ Although our patient presented with melanoma postpartum (a period in which there is a very important increase in the sex steroid hormones) and had used progestogen-based contraceptives after delivery, the tumor cells were negative for estrogen and progesterone receptors, which are known to lead to the action of these hormones on tumor cells to stimulate the proliferation of the tumor. This finding demonstrates that, at least in this case, the cause of the neoplasm was not related to the rise in sex steroid hormones.

The prognosis of primary vaginal melanoma is very poor due to extensive angiolymphatic invasion. Regardless of the therapy chosen, less than $10 \%$ of the patients survive for more than 5 years. ${ }^{4}$ In the present case, our patient died one year after the diagnosis.

Since the 1950s, there have been several published case reports and series describing pregnancy as a factor for the transformation of a melanocytic nevus into a malignant melanoma, and as a trigger for metastasis in existing melanomas. Gestational melanomas are called pregnancy-associated malignant melanomas (PAMMs), and the diagnosis can be made one year before pregnancy, during pregnancy or up to five years postpartum. ${ }^{5}$ Our patient was diagnosed two months postpartum; therefore, she was classified as having a PAMM.

Pregnancy induces a state of relative immunosuppression that is considered an adaptation to accommodate the growing fetus that contains paternal antigens extraneous to the maternal organism. Additional evidence has suggested that pregnancy-related hormonal changes have a direct effect on melanomas. The argument that melanomas have a hormonally responsive component is supported by reports that show changes in skin pigmentation during pregnancy, increased incidence of melanoma after puberty, and presence of progesterone and estrogen receptors in a portion of patients with melanoma. ${ }^{6}$ The progesterone and estrogen receptors in the tumor were negative in this case; therefore, the greatest influence on the patient's prognosis may be related to immunosuppression caused by pregnancy.

Although there are a limited number of studies on the subject, it appears that pregnancy does not influence the prognosis of melanomas. The prognostic parameters are the same for pregnant and non-pregnant patients. ${ }^{6}$ In the present case, it is difficult to differentiate whether the poor prognosis of our patient was associated with gestation or if it was simply attributable to a genital melanoma, which already has a poor prognosis. This issue demonstrates that further studies are needed to assess the true influence of pregnancy on melanomas, not only of the genitalia, but also of other areas. 




Fig. 4 Positron Emission Tomography/computed tomography (PET/CT) scan with fluorine-18 fluorodeoxyglucose (FDG-18F). (A) Hypermetabolic expansive lesion in the uterine cervix and hypermetabolic lesions of the liver and right kidney. (B) Hypermetabolic expansive lesion in the uterine cervix. (C) Hepatic hypermetabolic lesions. (D) Hypermetabolic lesions in the right kidney.

Most cutaneous melanomas have NRAS and BRAF gene mutations, although these mutations are rarely detected in mucosal melanomas. Thus, therapies directed at RAS-RAF (sorafenib) pathways may not be useful for the treatment of genital melanoma. C-KIT is an important oncogene in melanoma, and mutation of exon 11 has been frequently detected in mucosal melanomas. ${ }^{7}$ Imatinib and sunitinib have induced a clinical response in patients with metastatic mucosal melanoma and a demonstrated mutation of $c-K I T{ }^{7}{ }^{7}$ Two targeted therapies, ipilimumab, a CTLA-4 blocking antibody, and vemurafenib, a $B R A F$ inhibitor, have recently been approved for advanced urogenital melanoma. ${ }^{2}$ Anti-programmed death-ligand-1 (anti-PD-L1) agents, such as nivolumab, when used as monotherapy, result in a lower risk of adverse events compared with ipilimumab. However, combination strategies are associated with a significant increase in the incidence of toxicity and higher rates of treatment discontinuation. ${ }^{8}$ In this case, although mono- therapy with nivolumab was used, our patient presented with hepatic failure, which led to the suspension of the treatment, showing that new therapies with less toxicity are still necessary for the treatment of melanomas in advanced stages.

Postpartum vaginal bleeding, even if late-onset, should be investigated, since these cases may be associated with postpartum malignancies and vaginal melanoma. Even though postpartum genital melanoma is a rare neoplasm, it should be considered in the differential diagnosis.

\section{Conflicts of Interest}

The authors have no conflicts of interest to disclose.

\section{Acknowledgments}

The authors are grateful to Dr. Luiz Antonio Bugalho for providing radiological images of the case and to Bacchi Laboratory - Consulting Pathology for providing the slides. 


\section{References}

1 Andersson TM, Johansson AL, Fredriksson I, Lambe M. Cancer during pregnancy and the postpartum period: A populationbased study. Cancer 2015;121(12):2072-2077. Doi: 10.1002/ cncr.29325

2 Ferraioli D, Lamblin G, Mathevet P, et al. Genital melanoma: prognosis factors and treatment modality. Arch Gynecol Obstet 2016;294(05):1037-1045. Doi: 10.1007/s00404-016-4144-4

3 Myriokefalitaki E, Babbel B, Smith M, Ahmed AS. Primary malignant melanoma of uterine cervix FIGO IIa1: A case report with 40 months ongoing survival and literature review. Gynecol Oncol Case Rep 2013;5:52-54. Doi: 10.1016/j.gynor.2013.04.004

4 Chen L, Xiong Y, Wang H, Liang L, Shang H, Yan X. Malignant melanoma of the vagina: A case report and review of the literature. Oncol Lett 2014;8(04):1585-1588. Doi: 10.3892/ ol.2014.2357
5 Johansson AL, Andersson TM, Plym A, Ullenhag GJ, Møller H, Lambe M. Mortality in women with pregnancy-associated malignant melanoma. J Am Acad Dermatol 2014;71(06):1093-1101. Doi: $10.1016 /$ j.jaad.2014.09.018

6 Todd SP, Driscoll MS. Prognosis for women diagnosed with melanoma during, before, or after pregnancy: Weighing the evidence. Int J Womens Dermatol 2017;3(01):26-29. Doi: 10.1016/j.ijwd.2016.12.004

7 Quintás-Cardama A, Lazar AJ, Woodman SE, Kim K, Ross M, Hwu P. Complete response of stage IV anal mucosal melanoma expressing KIT Val560Asp to the multikinase inhibitor sorafenib. Nat Clin Pract Oncol 2008;5(12):737-740. Doi: 10.1038/ncponc1251

8 Friedman CF, Proverbs-Singh TA, Postow MA. Treatment of the immune-related adverse effects of immune checkpoint inhibitors: a review. JAMA Oncol 2016;2(10):1346-1353. Doi: 10.1001/ jamaoncol.2016.1051 